\title{
Congress grabs eugenics common ground
}

[BEIJING] Scientists gathered at the International Congress of Genetics have warned against the use of genetic testing as a coercive tool of public policy. They call for all genetic counselling to be based on the principle of informed choice by individuals and their families.

A workshop on the science and ethics of eugenics agreed that governments should consult the scientific community on all genetics-related issues, and argued that the term 'eugenics' is currently used in so many ways "as to make it no longer suitable for use in scientific literature". Eight conclusions (see box) emerged from the workshop, which took place during the eighteenth International Congress of Genetics, held in Beijing under the auspices of the International Genetics Federation (IGF).

Although the topic of eugenics has been frequently discussed at the IGF's five-yearly congress, it attracted particular attention this year. This was because China adopted in 1994 what was initially called a 'eugenics law', which suggested that people suspected of having a 'serious genetic disease' might face compulsory sterilization if they wished to marry (see Nature 367, 3; 1994).

Chinese officials say that the main thrust of what has been subsequently renamed the Law on Maternal and Infant Health Care is a concern to provide a wide range of pre- and post-natal services. They say that concern outside China has been primarily the result of "ambiguities" in the wording of the section on genetic counselling.

Nevertheless such concern has led to considerable protest by groups ranging from US anti-abortionists to supporters of ethnic groups in Tibet. The Beijing meeting was boycotted by the professional genetics organizations of Britain, Holland and Argentina.

Last week's workshop was organized by the IGF as a dialogue with Chinese geneticists in a bid to stop the boycott from spreading further, and to placate those who wanted the meeting moved to another country as a protest. It was organized by Anthony Griffiths, professor of genetics at the University of British Columbia in Canada, who says that events in China have given the debate "a razor-sharp edge".

Two articles in the Chinese law have attracted particular attention. Article 10 says that if anyone intending to marry is diagnosed with "a genetic disease of a serious nature", the couple must agree to long-term contraception or sterilization. Under Article 16 if a physician "detects or suspects" such a disease in a married person, the couple should take "corresponding measures according to the physician's medical advice".

Qiu Ren-Zong, of the Chinese Academy of Social Sciences, argued at the workshop

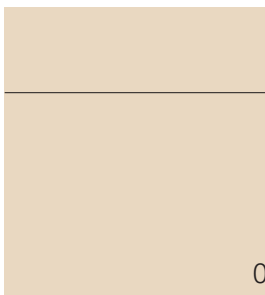

6.

3.

0

4.

7.

1

that much of the controversy had been the result of the naïve use of the term 'eugenics' for the Chinese word yousheng, which he said can also mean 'healthy birth', with none of the negative connotations which the word has developed in the West.

Qiu emphasized that the law also has an economic function, in that China currently faced a significant bill in supporting its estimated 50 million disabled people. But he admitted that the "ambiguous" wording of articles 10 and 16 could be interpreted as giving doctors the power to require sterilization on the basis of a rudimentary diagnosis of particular symptoms being genetic in origin.

Several other speakers pointed out that the goals of the law could be given a more positive interpretation. Anne McLaren, for example, of Britain's Wellcome/CRC Institute at Cambridge, quoted one dictionary definition of eugenics as "pertaining to the protection of fine offspring", and said that many women in the West already take steps to achieve this. "We should either ban the term 'eugenic', or restore a definition in line with the Chinese meaning," she said.

Some speakers expressed particular concern at the way in which the law appears to give greater importance to the well-being of social groups than that of the individual. Qiu explained that this approach was not just a product of the socialist regime that has ruled China since 1949, but had been central to Chinese culture for many centuries.

Critics included Valery Soyfer, a prominent Russian agricultural geneticist and former dissident who now teaches at George Mason University in the USA. Soyfer argued that the Chinese position contradicted the United Nations Universal Declaration of Human Rights, which says that top priority should be given to the rights of individuals.

In response, Qiu argued that, even if the meaning had been clouded by ambiguity in the language, one of the main themes of the controversial articles was the importance of what the West calls 'informed consent'.

"We must make clear that Chinese 'eugenics' is not the eugenics of Nazism, racism or genetic discrimination," he said. "Our only concern is to improve the health of the next generation."

Despite some sharp differences of opinion during the meeting, there was sufficient convergence of views - for example, on endorsing the concept of 'informed choice' as central to the use of genetic data in reproductive decisions - to lead to the decision to draw up a document expressing what Griffiths described as "a communal sentiment".

Presenting these to the final plenary session of the congress, he pointed out that the principles listed had implications that reached further than the issue of eugenics. "Geneticists have a broad responsibility to inform others about their science and its consequences for public health," Griffiths said. "If people do not fully understand what genetics is and is not capable of achieving, it is partly our fault."

The concerns of the meeting's critics appear to have been assuaged to some extent. Newton Morton, a British geneticist who chose to stay away from Beijing, describes the workshop's conclusions as "a splendid statement, and much more forthright than anything I had expected".

Morton, a professorial fellow in human genetics at the University of Southampton, says the conclusions were clearly "skillfully manoeuvred to win the support of the Chinese government to remove ambiguities in the law". But he adds that it remains to be seen whether the law is changed, or whether the workshop, and its conclusions, "rebound on Chinese geneticists".

DavidDickson 